\title{
Digitale Abformung: Experten bringen Licht ins Dunkel
}

Die Verbreitung von Intraoralscannern und deren Einfluss auf Arbeitsprozesse in Praxis und Labor nimmt stetig zu. Alle potenziellen Anwender sollten darum umfassend informiert sein. Doch während Basisinformationen leicht zu beschaffen sind, bleiben konkrete Fragen rund um die Investition und Integration häufig unbeantwortet. Für Klarheit sorgt die Teilnahme am Seminar „Hand in Hand zu passgenauer Prothetik - Digitale Abformung als Bindeglied zwischen Praxis und Labor".

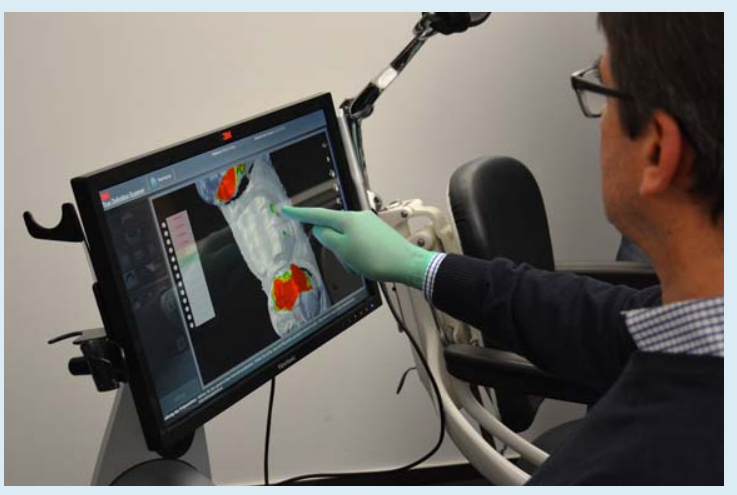

Einer der 1. Kurse der von $3 \mathrm{M}$ organisierten Veranstaltungsreihe fand im Dezember 2015 bei Core3dcentres Berlin statt. Die Referenten Dr. Helmut Kesler (Berlin) und ZTM Hans-Jürgen Stecher (München) widmeten sich diversen Intraoralscannern, unterschiedlichen Workflow-Optionen des 3M True Definition Scanners sowie individuellen Fragen der Teilnehmer. Die Fortbildung in kleiner Runde ermöglichte es den Referenten, detailliert auf individuelle Fragen einzugehen. Wer ebenfalls von dem umfassenden Know-how seiner erfahrenen Kollegen profitieren möchte, erhält dazu am 15. April 2016 in Hamburg, am 20. April 2016 in Karlsruhe, am 27. April 2016 in München und am 10. Juni 2016 in Berlin die Gelegenheit. Beginn ist jeweils 15:30 Uhr. Weitere Informationen unter www.3MESPE.de oder 08002753773. 